\title{
Conversion of Sponge Iron From Low Grade Iron ore And Mill Scale Through Simulating Tunnel Kiln Condition
}

\author{
Rounak Sneh Anand ${ }^{1}$, Prakash Kumar ${ }^{2}$, Dr. D.N.Paswan ${ }^{3}$ \\ ${ }^{1}$ Post Graduate Student, Department of Mechanical Engineering, BIT Sindri, Dhanbad India \\ ${ }^{2}$ Assistant Professor, Department of Production Engineering, BIT Sindri, Dhanbad, India \\ ${ }^{3}$ Principal Scientist, CSIR-National Metallurgical Laboratory, Jamshedpur, India
}

\begin{abstract}
The present investigation deals with the feasibility study of the process development for production of Directly Reduced Iron (DRI) using waste/low grade iron ore (slime), mill scale and waste/less reactive coal (partly oxidized coal i.e. Jhama coal). In order to get most green and dry strength for safe handling and transportation, the pellets of iron ore slime and the pellets of mill scale were made in disc pelletizer with optimum moisture. Dried iron ore slime pellets reduced the bed of Jhama coal fines at different temperature and sintering time. Detailed investigation for the reduction kinetics of slime pellets with Jhama coal has been carried out to explore the feasibility of slime pellets reduction. Based on reduction kinetics, process criterion for reduction of pellets with Jhama coal is optimized to produce highly metallic DRI. The Reduction of dried pellets was carried out without in duration/firing higher temperature as compared to the conventional DRI process yielding high energyefficient and cost-effective process. An optimized work flow sheet and innovative process has been developed for production of high quality DRI utilizing waste iron ore slime and less reactive coal (Jhama coal). The DRI produced from this process have high metallization (<92\%) suitable for blast furnace and electrical for iron and steel making.
\end{abstract}

\section{Introduction}

Mill scale is an iron oxide waste generated during steelmaking process, casting and rolling. The mill scale contains very high percentage of iron which is generated during making of steel towards production of various long and flat products. The major part of mill scale in an integrated steel plant is recycled for in house consumption; but no commercial process for its utilization is so far available for the secondary sector in industries. So it is either dumped or exported at a very low price. It is appeared on the outer surfaces of plates, sheets or profiles when they are being produced by rolling red hot iron or steel billet in rolling mills. It is composed of iron oxides mostly ferric and is bluish black in color. It is regularly less than $0.1 \mathrm{~mm}$ (0.0039 in) thick and initially adheres to the steel surface and protects it from atmospheric corrosion contributed no break occurs in this coating. Here some preliminary results of a laboratory scale investigation has been done which involves pelletization of mill scale, using steel plant waste as an additive and following reduction of the air dried pellet by non-cooking coal fines under conditions, simulating a tunnel kiln. The results of this investigation indicate that the green pellets could be successfully handled, without generating much of fines and could be change to highly metalized Directly Reduced Iron (DRI) at a moderate temperature and at a reasonably low heating time.Mill scale, a high iron containing body was thus used as a waste for a long time and was dumped. However, in recent past a convincing part of mill scale is being exported to China at a very low price. Though a small amount of mill scale is utilised in ferroalloys, cement and petrochemicals industry, there is a potential for production of almost 1.0 Mt of steel, alike with the current level of mill scale generation. All the above calls for an initiative to find satisfactory means for effective utilization of mill scale. The generation of steel and corresponding mill scale in India is given in figure $\mathbf{1}$.

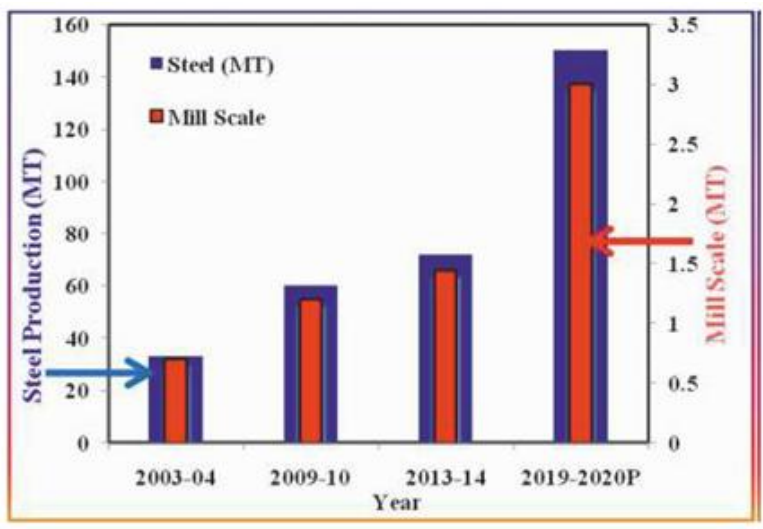


In 2003-04, the production of mill scale was only 0.7MT in India while the production of steel was almost some greater than 25MT. After some year in 2009-10, the production of steel was increases and it achieved 60MT. In 2003-04, the production of mill scale was only 0.7MT in India while the production of steel was almost some greater than 25MT. After some year in 2009-10, the production of steel was increases and it achieved 60MT. That's mean the production of mill scale was obviously increased and it reached to the 1.20MT. But in 2013-14, the rapidly growth in the production of steel and it achieved 70 MT while the production of mill scale also increased by $1.45 \mathrm{MT}$.In steel production, India is also expected to leave behind USA and Japan in couple of years according to given data. In 2019-20, as per expectation the production of steel will be $150 \mathrm{MT}$ and the production of mill scale will be $3 \mathrm{MT}$ [1].

Mill scale is very tempting industrial waste because of its richness in iron (about $=72 \% \mathrm{Fe}$ ). Mill scale is a solid by product of the steelmaking industry that contains metallic iron (Fe) and three types of iron oxide: wustite $(\mathrm{FeO})$, hematite $\left(\mathrm{Fe}_{2} \mathrm{O}_{3}\right)$ and magnetite $\left(\mathrm{Fe}_{3} \mathrm{O}_{4}\right)$.Irrespective of the products, during processing of steel to yield long or flat product, mill scale is produced during hot rolling and considered as a waste. The generations of mill scale represent about $2 \%$ of steel produced and it available as a secondary material due to its richness in iron (about $72 \% \mathrm{Fe}$ ). More than 1.4 million tons of mill scales are generated yearly in India and is expected to reach about 3.0 million tons by 2020. In an integrated steel plant, almost $85 \%$ of the mill scale, generated is consumed in-house through sintering. The balance part of the mill scale with particle size less than $0.5 \mathrm{~mm}$ is heavily contaminated with oil and is dumped for land filling as waste. This has combined dimensional effect including cost of disposal and environmental pollution. The integrated steel industries comprise most of the mild steel production in India. Their main products include flat products like hot rolled, cold rolled and galvanized steel. They also produce long and special steel in small quantities ${ }^{[1]}$. The recycling of wastes generated in integrated steel plants currently can be realized by using one or two of five methods, which involve sintering, cold bonded agglomeration, injection, direct reduction (DR) and smelting reduction. The choice of one of these methods depends on big important factors such as the environmental requirements, energy policy, industries statues, and industries strategies in recycling, feasibility concerning economy and technology. Mill scale (3-7\% of the total steel rolling) is a expensive secondary material due to its high iron content, low impurities and stable chemical composition. The mill scale from the rolling process and all iron bearing wastes generated at the iron and steel plant site are commonly recycled into the sintering plant to produce high quality sinters. The use of such sinter ( low silica and gangue materials ) leads to decrease the blast-furnace fuel rate through reducing slag volume, permitting stable furnace operation as a result of enhance high temperature properties, and reducing the cost of sub-raw materials. The recycling and use of iron-bearing by-products such as dust, scale and sludge have long been promoted in iron and steel-making plant due to their various benefits which are: (i) to reduce the depletion of the earth's limited natural resources;(ii) to reduce pollution generated by discharging untreated waste; and (iii) to save energy indirectly[2].The secondary sector comprises small units which are particularly focused on the production of value added products by melting of scrap or sponge iron or suitable mixture of the two compositions. This sector produces long steel product in form of angles, columns, beams, bars and different re-rollers and accounts for over $50 \%$ of the total indigenous output. The scenario is slightly different for the secondary sector. The credit for producing approximately $90 \%$ of the structural steel, consumed in India, is set down to the secondary sector. This category of steel undergoes hot rolling during processing and generates an important quantity of mill scale. The individual production units being small and scattered all over the country, no orderly effort has been made so far for its collection and commercial exploitation. Further, the absence of a sinter making provision in such production units does not offer any scope for in-house recycling of mill scale [3].Direct Reduced Iron (DRI) is produced from iron ore powder through heating and chemical reduction by natural gas/ coal. While this is in general more expensive process than reducing the iron ore in the blast furnace, but there are certain factors that can make it economical:

$>$ Direct reduced iron is richer in iron than pig iron

$>$ excellent feedstock for electric furnaces used by mini Mill,

$>$ Allowing them lower grades of scrape for the rest of the charge.

$>$ The direct reduction process uses powdered iron ore, avoiding the sintering process

The direct reduction process can use natural gas contaminated with inert gases, avoiding the need to these gases for other use [4]. The process of DRI or sponge Iron making can be classified into different categories as given below:

\section{(A) Rotary Klin Process}

Rotary Kiln method is very important for sponge iron production using non-coking coal as a reluctant. The Iron ore is charged from one end with non-coking coal which is in the lump form or pellets and heated from the other end, thus carrying counter current movement of raw materials and gases. The reduced ore comes out as product from opposite end. During reduction the rotary movement of the kiln requires good strength of raw materials. Generation of fines from poor raw material promotes ring formation leading to poor performance and decreased productivity. 


\section{(B) Rotary Hearth Process}

The iron oxide fines, coal fines and binder are mixed together and palletized in this process .The green pellets are located on a rotating hearth. As the hearth rotates around the circular furnace, the pellets are heated to $1250^{\circ} \mathrm{C}-1350^{\circ} \mathrm{C}$ and the reduction of iron oxide to metallic iron. Reduction of iron oxide is accomplished by the carbon contained in the pellets. Residence time in hearth is around 15-25 minutes during which $90-95 \%$ of iron oxide is converted in to metallic iron. Burner fuel for RHF can be in the form of pulverized coal, natural gas, and coke oven gas, coal oil mixture. Volatiles and $\mathrm{CO}$ gas evolved from the pellets is combusted within the RHF thus providing a significant portion of total heat requirement. The DRI generated from the RHF is fed to an electric meter called Electric Iron making Furnace (EIF) to produce a high quality liquid iron known as FASTIRON [5].

World crude steel production has been increased by almost 1.6 times when the world entered in the new millennium. Its production has acquired 1606 million tons in 2013 with the annual average growth of $6.3 \%$ per annum after 2000[6]. India has emerged as the $4^{\text {th }}$ largest producer of steel $(81.36 \mathrm{MT})$ in 2013-14 with 10.8 percent growth rate as compared to 2011-12 (73.42MT). The need of steel in India is expected to rise by 7\% in the coming financial year and expected to going 200 million tons by 2020 as compared to 83.36 MT in the current year [7]. In steel production, India is also expected to leave behind USA and Japan in couple of years. The requirement of huge quantities of steel in India is fulfilled by primary and secondary sectors of steel industries. The primary sector comprises of a few large integrated steel industries which produces steel, staring from iron ore. The integrated steel industries constitute most of the mild steel production in India. Their main products comprise flat products such as hot rolled, cold rolled and galvanized steel. They also produce long and special steel in low quantities. On the other hand secondary sector comprises small units which are particularly target on the production of value added products by melting of scrap or sponge iron or suitable mixture of the two. This sector make long steel product in form of angles, columns, beams, bars and other re-rollers and accounts for over 50 per cent of the total indigenous output[8,9]. Both sectors cater up to $95 \%$ non alloys steel production and remaining is alloys steel. In 2010-11, out of total non alloys production, long steel product constitutes $50.1 \%$ and remaining $49.1 .3 \%$ was flat products and is expected to be $48.8 \%$ and $51.2 \%$ respectively in coming 2016-17[10].

\section{Objective}

$>$ To optimize the binder and moisture content for pellets making with mill scale and waste/low grade iron ore (slime)

$>$ To studies the feasibility of DRI production utilizing mill scale and waste carbonaceous material to produce highly metalized reduced iron suitable for iron and steel making.

$>$ To optimize the reduction temperature and time to yield highly metalized reduced iron with high cold crushing suitable for blast furnace, induction furnace, electric furnace iron and steel making process.

$>$ To develop a process for production of DRI utilizing low grade iron ore (slime) and less reactive coal (Jhama coal) suitable for iron and steel making.

\section{Experimental Work}

The two compositions of pellets are prepared. In first composition the percentage of mill scale is $100 \%$ and in the second composition the percentage of mill scale is $90 \%$ and the percentage of slime is $10 \%$. The mill scale and slime were grinned to get the -92 mesh size particle for preparation of pellets. The very first step of pellet preparation was to take the required weight of mill scale and slime in percentage and water, binding agent. The required percentage of binder $(1 \%)$ was added to the mixture of mill scale and slime in order to get optimum strength for handling and transportation. The mill scale and slime were thoroughly mixed by hand rolling as well as in the disc pelletizer to get the pellets in the size range of $20-26 \mathrm{~mm}$. The required quantity of water (12-23\%) was added by measuring in a beaker, to get a spherical green pellet of size $20 \mathrm{~mm}-26 \mathrm{~mm}$. The green pellets were kept in muffle furnace at $100 \pm 10^{\circ} \mathrm{Cfor} 1$ hour to evaporate the moisture present in the green pellets. The dried pellets were kept in the air sealed bottle with their identity number for further use in the experiment.

After preparation of pellets, low grade non-coking coal was grinded and screened to get -72 mesh size fines. Pellets were charged in a (220 $\mathrm{mm}$ inner diameter and $160 \mathrm{~mm}$ height) ceramic crucible in a predesigned fashion. The reduction of mill scale pellets were carried out in a laboratory scale, electrically heated muffle furnace, simulating conditions of a tunnel kiln, Pt-10\%pt-Rh thermocouple was used to measure the temperature of the furnace. A series of reduction experiments were carried out in the temperature range of $1000^{\circ} \mathrm{C}$ to $1250^{\circ} \mathrm{C}$.The reduction time of samples were varied from 30 minutes to 180 minutes. Counting of reduction time started only after attainment of the set temperature.To ensures complete reduction of mill scale pellets, the amount of non-coking coal used was $20 \%$ over the stoichiometric requirement. After that Muffle was switched 
off and allowed cool naturally and then the reduced pellets were taken out from crucible to measure the weight of pellets.

$\%$ degree of reduction $=\quad \mathrm{n}_{0}-\mathrm{n}$

Where,

$$
\mathrm{n}_{0}
$$

$\mathrm{n}_{\mathrm{o}}=$ number of moles of oxygen originally combined with iron only,

$\mathrm{n}=$ number of moles of oxygen left combined with iron after experimental time, $\mathrm{t}$.

\section{Reduction:}

\section{Results And Discussion}

The weighed dry iron pellet was kept in a bed of coal fines held in a ceramic crucible. This ceramic crucible was placed in a silicon carbide furnace and heated to the required temperature $\left(1000-1250^{\circ} \mathrm{C}\right)$ and sintering time (30-180 minute) for reduction. After reduction crucible were taken out and allowed to cool at room temperature. Thereafter, the reduced pellets were separated from coal fines.

\section{$>$ Reduction kinetic of iron ore slime pellets}

Reductions kinetic of pellets describe the rate of removal of oxygen from iron oxide to yield the metallic iron. The rate at which the iron oxide is reduced influences the rate of production, which determines the techno economic feasibility of the process. The reduction of iron oxide to metallic iron proceeds through various kinetic steps, which control the overall rate of reaction and referred as rate controlling steps. The different rate controlling factor which control the overall rate of reduction are given below.

\section{Reaction taking place during reduction:}

\begin{tabular}{|c|c|c|}
\hline S.No. & Reaction & Remarks \\
\hline 1. & $\mathrm{C}+\mathrm{O}_{2}=\mathrm{CO}_{2}$ & \multirow{4}{*}{ Gasification of carbon } \\
\hline 2. & $\mathrm{C}+\mathrm{CO}_{2}=2 \mathrm{CO}$ & \\
\hline 3. & $\mathrm{C}+1 / 2 \mathrm{O}_{2}=\mathrm{CO}$ & \\
\hline 4. & $\mathrm{C}+\mathrm{H}_{2} \mathrm{O}=\mathrm{CO}+\mathrm{H}_{2}$ & \\
\hline 5. & $3 \mathrm{Fe}_{2} \mathrm{O}_{3}+\mathrm{CO}=2 \mathrm{Fe}_{3} \mathrm{O}_{4}+\mathrm{CO}_{2}$ & \multirow[t]{4}{*}{ Indirect reduction } \\
\hline 6. & $\mathrm{Fe}_{3} \mathrm{O}_{4}+\mathrm{CO}=3 \mathrm{FeO}+\mathrm{CO}_{2}$ & \\
\hline 7. & $\mathrm{FeO}+\mathrm{CO}=\mathrm{Fe}+\mathrm{CO}_{2}$ & \\
\hline 8. & $\mathrm{FeO}_{3}+3 \mathrm{CO}=2 \mathrm{Fe}+3 \mathrm{CO}_{2}$ & \\
\hline 9. & $2 \mathrm{Fe}_{2} \mathrm{O}_{3}+3 \mathrm{C}=4 \mathrm{Fe}+3 \mathrm{CO}$ & Direct reduction \\
\hline
\end{tabular}

\section{$>$ Boundary rate control}

In this process the overall reduction rate is controlled by the diffusion of gas and heat through the boundary layer of the gas which build up around each pellet. The rate of diffusion of the gas through the boundary layer is proportional to the concentration of gas around the pellets whereas the rate of heat flow to the pellets is proportional to the concentration of gas around the pellets whereas the rate of heat flow to the pellets is proportional to the temperature gradient across the boundary layer.

\section{$>$ Phase boundary reaction control}

The chemical reaction at the wustite-iron interface is the rate controlling factor. In this case the rate of reduction per unit area of the unreduced iron oxide is found to be constant with time. This mechanism is called "Phase Boundary Reaction Control". When counter diffusion of reducing gas and product gas on the reduced outer surface of iron oxide is sufficiently fast, the concentration of reducing gas at the reacting surface is effectively the same as its concentration at the particle surface. In such case the rate of reduction at wustite-iron interface would control
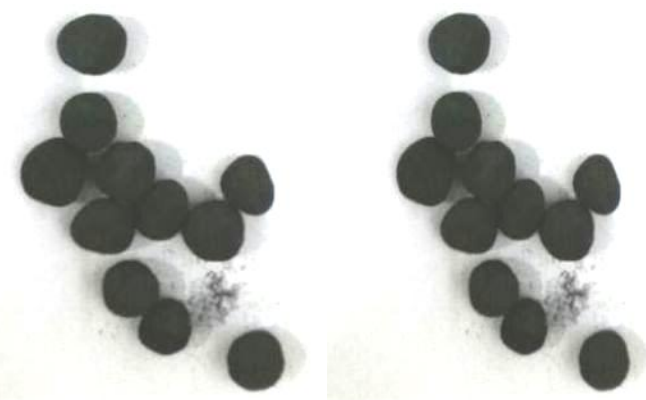

$100 \%$ mill scale for $1250^{\circ} \mathrm{c}$ in 180 minute 


\section{$>$ Gaseous diffusion control}

In the gaseous diffusion control the rate of flow of reducing gas towards the iron oxide and product gas coming out through the reduced iron whisker can control the rate of iron oxides reduction. This phenomenon is generally associated with large ore particle and is known as "Gaseous Diffusion Control". When gaseous diffusion is the rate controlling step, the rate of diffusion of reducing gas inward and product gas outward the porous layer of metallic iron surrounding the unreduced inner core particle, is slower than the rate of reaction. During such occurrence, the concentration of the reducing gas starts decreasing whereas product gas concentration starts increasing at the interface. The change in the gas composition on the interface decreases the reduction rate until pseudo steady state is established. This is the predominant rate controlling mechanism for high temperature reduction when reduced iron layer thickness exceeds about $1 \mathrm{~mm}$.

\section{$>$. Mixed control}

The mixed control mechanism occurs, when both gaseous diffusion control and phase boundary reaction control, influence the rate of reduction. Mixed control mechanism has been proposed by several experiments to recognize the complexities and conflicting results obtained from direct reduction of iron oxide with simpler mechanism as discussed above. In mixed control, mechanism, the gas boundary layer, the phase boundary reaction and gaseous diffusion act together under pseudo steady state condition to determine the overall reaction rate.

The reduction behavior of the pellet containing different percentage of mill scale is given in figure 2

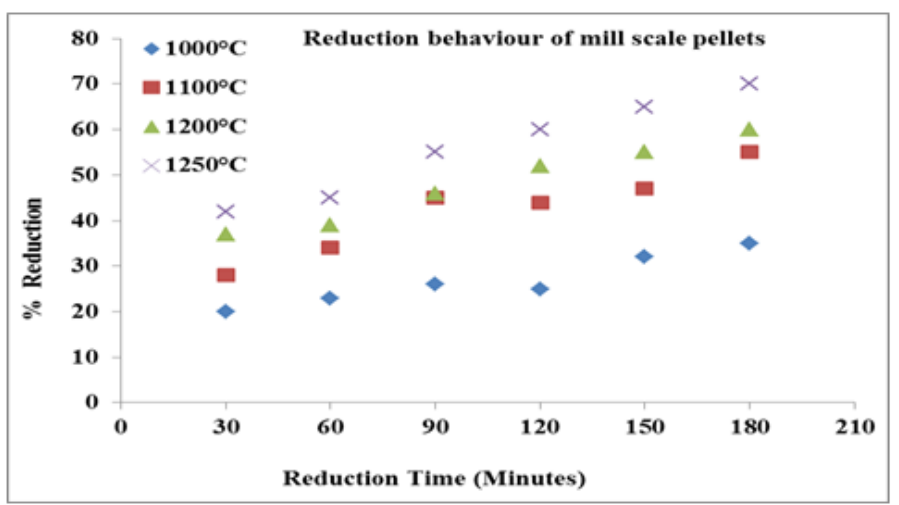

\section{Swelling and shrinkage behavior}

The pellets undergo volume change during reduction due to change in mineral phase and morphology of reduced iron. The volume of the pellets increases initially due to change in crystal structure followed by shrinkage due to sintering and fusion of reduced iron. This volume change was calculated by nothing the diameter of pellets before and after reduction assuming the pellets is spherical.

\section{a) Swelling/shrinkage behavior the pellets containing $100 \%$ mill scale:}

It is observed that pellets undergo shrinkage during reduction at all the reduction time (30-180 minutes) at all the reduction time $\left(1000\right.$ to $\left.1250^{\circ} \mathrm{C}\right)$. The maximum shrinkage was observed at 180 minutes of reduction time at $1250^{\circ} \mathrm{C}$. However, it can be noted that the shrinkage behaviour of the pellets in all the reduction time and temperature is more or less same. The shrinkage behaviour of the pellets containing $100 \%$ mill scale is given in the figure 3

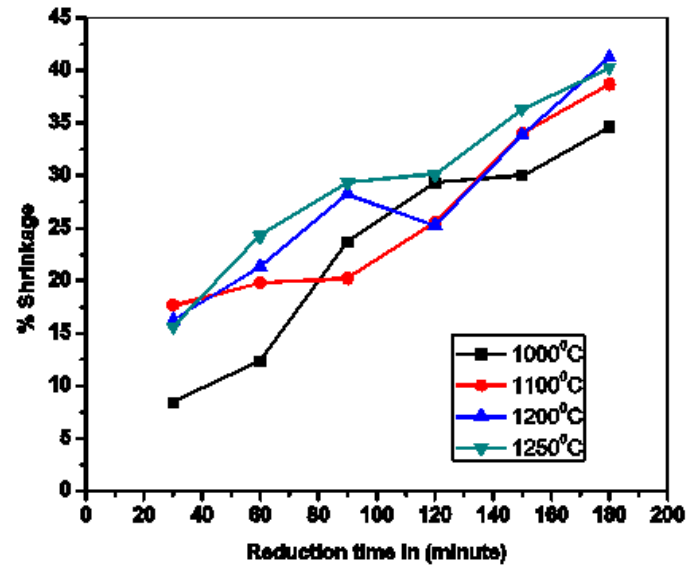


(b) Swelling/shrinkage behavior the pellets containing $90 \%$ mill scale:

It is observed that pellets undergo shrinkage during reduction at all the reduction time (30-180 minutes) at all the reduction time $\left(1000\right.$ to $\left.1250^{\circ} \mathrm{C}\right)$. The maximum shrinkage was observed at 180 minutes of reduction time at $1250^{\circ} \mathrm{C}$. However, it can be noted that the shrinkage behaviour of the pellets in all the reduction time and temperature is more or less same. The shrinkage behaviour of the pellets containing $100 \%$ mill scale is given in the figure 4

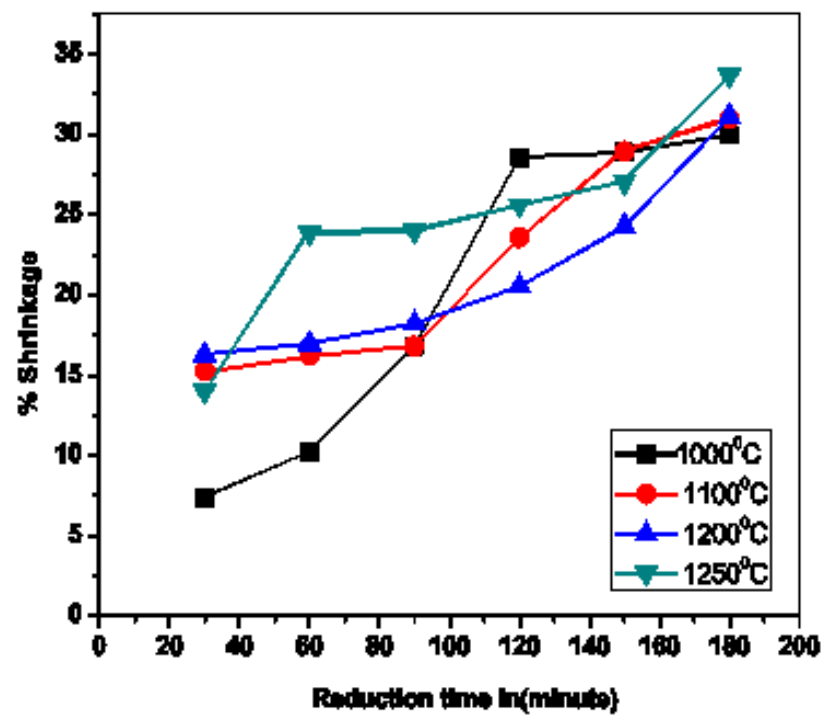

Comparison chart between both compositions:

\begin{tabular}{|l|l|l|}
\hline Property & $100 \%$ Mill Scale & $90 \%$ Mill Scale \&10\%Slime \\
\hline Strength & $\begin{array}{l}\text { High (Due To Mostly } \\
\text { Metallic Bond Present) }\end{array}$ & $\begin{array}{l}\text { Less (Due To Addition Of Low Grade Slime } \\
\text { Fines) }\end{array}$ \\
\hline Shrinkage & $\begin{array}{l}\text { High (More Shrinkage Better Dri Because Of } \\
\text { Maximum Removal Of } \mathrm{O}_{2}\end{array}$ & $\begin{array}{l}\text { Less (Minimum Removal Of } \mathrm{O}_{2} \text { As } \\
\text { Compared To 100\% Mil Scale Composition }\end{array}$ \\
\hline Reduction & High Reduction (More Reduction Get Better Dri) & Less Reduction \\
\hline Quality & Good & Low \\
\hline
\end{tabular}

\section{Conclusion}

During this investigation, different parameters affect the reduction of mill scale and quality of cast-able metal was studied. These parameters include the type and amount of reducing agent, their strength and shrinkage property. Waste slime fines can be used to produce high-grade Directly Reduced Iron (DRI) with mill scale. Overall, reduction of green pellets of mill scale appears to give an attractive way for utilizing waste.

Preliminary investigation has been carried out in a laboratory scale muffle furnace, simulating a tunnel kiln conditions, to produce DRI from air dried mill scale pellets and non coking coal fines. Pellets were found to undergo high degree of reduction at moderate temperature and at a reasonably low time. Overall, reduction of green pellets of mill scale in tunnel kiln appears to provide an attractive way for utilization of this high iron containing waste.

\section{Refrences}

[1] Mill Scale: A Potential Raw Material for Iron and Steel Making - Dayanand Paswan, M. Malathi, R.K. Minj \& D. Bandhyopadhayay, Steel world.

[2] Pradip, Beneficiation of alumina-rich Indian iron ores slimes, metals, materials \& process, vol. 6, no. 3, pp179-194, 1995

[3] M. Kumar and S.K. Patel, Characterizations of properties and reduction behavior of iron ores for application in sponge iron making. Mineral Processing and Extractive metallurgy Review, Vol. 29, 2008, pp. 258-273.

[4] O.Benchiheub et.al (2010) "Elaboration of iron powder from mill scale"

[5] Study of Reduction Behavior of Iron Ore Lumps by Binaya Mohapatra (10504004) and DharanidharPatra (10504021)

[6] “World steel in figures 2014”World Steel Association 2014, pp. 6 - 7: ISBN 978-2-930069-73-9.

[7] A brief report on Iron and Steel Industries in India, May 2014

[8] Public enterprises, government policy and impact on competition, Indian steel industry, Final Report, Prepared for the Competition Commission of India, January 2009, Indices' Analytics, New Delhi.

[9] India: poised to be the next steel giant 2013-1india: poised to be the next steel giant 2013-14, onicraredit rating agency of India. Steel Industries report, September 2013.

[10] (10) Long Term Perspectives for Indian Steel Industry, Dr. A.S.Firoz, Chief Economist, Economic Research Unit, $27^{\text {th }}$ May 2014 